\title{
The Utilization of Nitriles and Amides by a Rhodococcus Species
}

\author{
By J. M. MILLER† AND D. O. GRAY* \\ Department of Botany and Biochemistry, Westfield College (University of London), \\ Kidderpore Avenue, London NW3 $7 S T, U . K$.
}

(Received 5 August 1981; revised 3 December 1981)

\begin{abstract}
A species of Rhodococcus was isolated from garden soil on the basis of its capacity to use acetonitrile as sole $\mathrm{C}$ and $\mathrm{N}$ source. Acetonitrile-grown cells hydrolysed a number of amides and nitriles to ammonia. The substrate nitriles, listed in order of decreasing hydrolysis rates, were acetonitrile, acrylonitrile, propionitrile and $n$-butyronitrile. The corresponding amides were also hydrolysed together with formamide and, to a small extent, nicotinamide. With the exception of acrylonitrile and acrylamide, each compound supported growth as did the non-substrates malonamide, benzamide, $\alpha$-phenylacetamide and 3-aminopropionitrile. Benzonitrile, phenylacetonitrile (benzyl cyanide), malononitrile and aminoacetonitrile did not support growth. Nicotinamide and benzamide stimulated acetamidase activity but malonamide had no effect. Both the aminonitriles inhibited the acetonitrilase system. Cells grown in succinate $/\left(\mathrm{NH}_{4}\right)_{2} \mathrm{SO}_{4}$ medium did not hydrolyse acetonitrile or acetamide indicating that the enzymes involved in nitrile degradation are subject to induction/repression. Acetamide and acetate appear to be gratuitous inducers of acetonitrilase: acetate also induces the acetamidase.
\end{abstract}

\section{INTRODUCTION}

Aliphatic mononitriles are commonly metabolized in bacteria by stepwise hydrolysis to the corresponding carboxylic acid and ammonia. Thus the pathway for acetonitrile breakdown is:

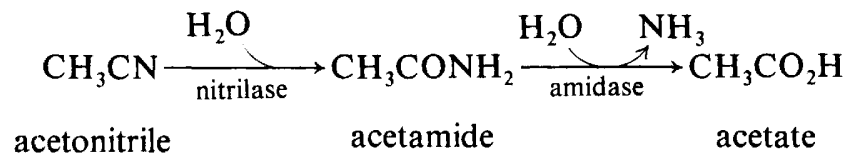

This reaction sequence was first suggested by Mimura et al. (1969) who found that ammonia and an amide, not specifically acetamide, accumulated in the medium when Corynebacterium nitrilophilus nov. sp. C-42 was grown on acetonitrile. Likewise, DiGeronimo \& Antoine (1976) observed the sequential formation of acetamide and acetate by Nocardia rhodochrous LL100-21 under similar conditions. The first step in the pathway was confirmed by showing transfer of ${ }^{14} \mathrm{C}$ from acetonitrile to acetamide in another nitrile degrader, a Pseudomonas sp. (group III; NCIB 10477) (Firmin \& Gray, 1976). The pathway was shown in Arthrobacter sp. J-1 to involve two distinct enzymes, a nitrilase (or nitrile hydratase) and an amidase (Asano et al., 1980).

Other nitriles which support bacterial growth when supplied as the sole source of $\mathrm{C}$ and/or $\mathrm{N}$ include a variety of unsubstituted aliphatic, alkyl and alkenyl mono- and di-nitriles (Mimura et al., 1969; Fukuda et al., 1971; DiGeronimo \& Antoine, 1976; Yamada et al., 1979. 1980), $\alpha$-hydroxynitriles (Grant, 1973; Yamada et al., 1979), $\alpha$-aminonitriles (Fukuda

+ Present address: Biological Laboratories. University of Kent, Canterbury CT2 7NJ, U.K. 
et al., 1971) aromatic nitriles (Harper, 1977) and the natural product ricinine (Robinson \& Hook, 1964).

Bacterial amidases have been most studied in species of Pseudomonas (Clarke, 1970, 1972) though these organisms are not known to utilize nitriles. Pseudomonas aeruginosa (PAC 1 wild-type) can only utilize acetamide and propionamide, whereas some strains of $P$. putida and $P$. acidovorans can also grow on $n$-butyramide (Clarke \& Richmond, 1975).

Arnaud et al. $(1976 a, b, c)$ studied amide and nitrile hydrolysis by intact cells of a number of bacteria. However, almost nothing quantitative has been published about the specificities of the nitrilase and amidase systems of such nitrile degrading bacteria. The present work was designed to provide such information by measuring the relative rates of hydrolysis of 16 amides and nitriles by a newly isolated organism, a species of Rhodococcus. It was also intended to study the effect of non-substrate amides and nitriles on these reactions and to investigate the regulation of the enzymes involved.

\section{METHODS}

Isolation. The bacterium was obtained from soil by enrichment culture in basal salt medium (BSM) containing $0.1 \%(\mathrm{v} / \mathrm{v})$ acetonitrile as sole $\mathrm{C}$ and $\mathrm{N}$ source. The purified isolate was identified as a Rhodococcus species by the NCIB.

Media. The BSM was that of Firmin \& Gray (1976) except that $\left(\mathrm{NH}_{4}\right)_{2} \mathrm{SO}_{4}$ was normally omitted. It was sterilized by autoclaving at $103.5 \mathrm{kPa}\left(15 \mathrm{lbf}\right.$ in $\left.{ }^{-2}\right)$ for $15 \mathrm{~min}$, together with any added sodium acetate $(1 \%, \mathrm{w} / \mathrm{v})$, sodium succinate $(1 \%, \mathrm{w} / \mathrm{v})$ or $\left(\mathrm{NH}_{4}\right)_{2} \mathrm{SO}_{4}(0 \cdot 1 \%, \mathrm{w} / \mathrm{v})$. Nitriles and amides were introduced through sterile membrane filters (Oxoid, $0.45 \mu \mathrm{m})$ as a 5 to $10 \%(\mathrm{w} / \mathrm{v}$ or $\mathrm{v} / \mathrm{v}$ ) solution in BSM. Acrylonitrile, benzonitrile and phenylacetonitrile could not be filter-sterilized. Aqueous acrylonitrile attacked the membranes while the other nitriles were insufficiently soluble. Therefore, these compounds were each transferred aseptically directly to the culture medium. None of them supported growth, so the result was unambiguous.

Growth studies. All cultures were grown at $25^{\circ} \mathrm{C}$ in a linear shaker. Starter cultures $(50 \mathrm{ml})$, inoculated from plates, were centrifuged aseptically at $12100 \mathrm{~g}$ for $10 \mathrm{~min}$ and the cells resuspended to the same volume in sterile phosphate buffer $(0 \cdot 1 \mathrm{M}$-sodium phosphate, $\mathrm{pH} 7.0)$ to provide an inoculum $(5 \mathrm{ml})$ for the test medium $(95 \mathrm{ml})$. Samples were then removed aseptically at intervals and their $A_{640}$ recorded.

To study the effect of acetonitrile concentration on yield, starter cultures were grown in BSM containing $0.1 \%$ $(\mathrm{v} / \mathrm{v})$ acetonitrile for $2 \mathrm{~d}$ and then transferred to fresh BSM containing various concentrations of acetonitrile.

The ability of various nitriles and amides to support growth was also investigated. Starter cultures were grown for at least $4 \mathrm{~d}$ usually in BSM containing $\left(\mathrm{NH}_{4}\right)_{2} \mathrm{SO}_{4}$ and sodium acetate. When succinate was to be used subsequently as an additional $C$ source, acetate was replaced by sodium succinate. The test medium was BSM containing the relevant nitrile or amide (final concentration $0.5 \%, \mathrm{w} / \mathrm{v}$ or $\mathrm{v} / \mathrm{v}$ ). Where appropriate, an additional $\mathrm{N}$ source $\left[\left(\mathrm{NH}_{4}\right)_{2} \mathrm{SO}_{4}\right]$ or an additional $\mathrm{C}$ source (acetate or succinate) was also introduced.

Growth of cultures used for enzyme assays. Starter cultures $(5 \times 50 \mathrm{ml})$ were grown in BSM plus $0.25 \%(\mathrm{v} / \mathrm{v})$ acetonitrile for $3 \mathrm{~d}$ as before and then transferred to $4750 \mathrm{ml}$ of the same medium in a 151 aspirator. The culture was vigorously aerated with sterile filtered air supplied by a Hy-flo pump (Medcalf Bros, Potters Bar, U.K.). It was harvested using a Sharples continuous centrifuge (Pennwalt, Camberley, U.K.) at late-exponential phase (about 24 $\mathrm{h}$ growth), when total nitrilase and amidase activities were maximal: these activities decreased sharply during the stationary phase. The cells were resuspended to $100 \mathrm{ml}$ in $0.1 \mathrm{M}$-sodium phosphate buffer $(\mathrm{pH} 7 \cdot 0)$, giving a concentrated suspension containing typically $10 \mathrm{mg}$ dry weight cells $\mathrm{ml}^{-1}$.

Preparation of cell extracts. All stages were carried out at 0 to $4^{\circ} \mathrm{C}$. Cell extracts were prepared by sonicating $50 \mathrm{ml}$ of the concentrated cell suspension for a total of $30 \mathrm{~min}$ using a $150 \mathrm{~W}$ Dawe Soniprobe (Dawe Instruments, London, U.K.). The probe was cooled in ice/water for $30 \mathrm{~s}$ and then used to sonicate the suspension for $1 \mathrm{~min}$; the cycle was then repeated. The sonicated suspension was centrifuged at $17400 \mathrm{~g}$ for $15 \mathrm{~min}$ and the supernatant fraction retained.

Estimation of nitrilase and amidase activities. Rates of ammonia liberation from the test nitriles and amides were determined. Intact cells released this ammonia into the medium so the enzymes could be assayed in situ. The nitrilase assay made use of the natural coupling between nitrilase and the endogenous amidase.

The assay was done at $25^{\circ} \mathrm{C}$ and all components were pre-equilibrated to this temperature. Bacterial suspensions were diluted with an equal volume of $0.1 \mathrm{M}$-sodium phosphate buffer $(\mathrm{pH} 7.0)$ containing sufficient nitrile or amide to give a final concentration of $0.05 \mathrm{M}$. The reaction mixture was normally incubated until 2 to $6 \%$ of the substrate had been hydrolysed to ammonia. If hydrolysis was rapid, the cell suspension was further diluted with buffer. If hydrolysis was slow, the incubation period was extended to $30 \mathrm{~min}$ for amides and $120 \mathrm{~min}$ for nitriles. 
The reaction was terminated by mixing $0.5 \mathrm{ml}$ samples with $0.5 \mathrm{ml} 0.02 \mathrm{M}$ aqueous $\mathrm{AgNO}_{3}$ in a microdiffusion vessel, and then $1.0 \mathrm{ml}$ saturated aqueous $\mathrm{K}_{2} \mathrm{CO}_{3}$ was added. The $\mathrm{K}_{2} \mathrm{CO}_{3}$ would not, by itself, terminate the reaction effectively. Microdiffusion was carried out by a modification of the technique described by Etherington \& Morrey (1967) for $2 \mathrm{~h}$ at room temperature with continuous agitation. Ammonia recovered in the acid trap was measured using Nessler's reagent (BDH diluted 20-fold with deionized distilled water) and the absorbance at $420 \mathrm{~nm}$ recorded. Standard $\left(\mathrm{NH}_{4}\right)_{2} \mathrm{SO}_{4}$ samples were included in each set of determinations. Results were corrected for chemical decomposition of the substrates, which was substantial in the case of formamide.

Transferase activity was estimated by the method of Brammar \& Clarke (1964) except that $0 \cdot 1 \mathrm{M}$-sodium phosphate buffer, pH 7, was used and the incubation temperature was $25^{\circ} \mathrm{C}$.

The hydrolase and transferase activities were related to cell dry weights, measured by washing concentrated bacterial suspensions once with water and drying $1.0 \mathrm{ml}$ samples at $105^{\circ} \mathrm{C}$ for $2 \mathrm{~h}$.

Attempts to detect aminonitrile hydrolysis by NMR. Acetonitrile-grown cells were incubated with either aminoacetonitrile hydrochloride or 3-aminopropionitrile fumarate as for the usual enzyme assays, except that the incubation period was $5 \mathrm{~h}$. These suspensions $(5 \mathrm{ml})$ were centrifuged at $2500 \mathrm{~g}$ for 10 min and the supernatant fractions evaporated to dryness in vacuo at $25^{\circ} \mathrm{C}$. The residues were taken up in $0.5 \mathrm{ml} \mathrm{D}_{2} \mathrm{O}$ and examined with a $100 \mathrm{MHz}$ NMR spectrometer (Varian Associates, Palo Alto, U.S.A.). The spectrometer was capable of distinguishing between nitriles and their corresponding amides, at least for acetonitrile and aminoacetonitrile.

Enzyme induction studies. The Rhodococcus sp. was grown in 51 batch culture as before except that acetonitrile was replaced by alternative $C$ and $N$ sources: starter and test media were normally identical. If acetamidase activity was not detectable, acetonitrile hydrolysis was assayed indirectly by measuring the rate of ammonia production in the presence of Pseudomonas putida PPE1 (A87). This organism was grown in an acetamide-containing medium (Kelly \& Clarke, 1962) to induce aliphatic amidase activity (Clarke, 1972) but no nitrilase activity was detected. The reaction mixture, containing $2 \mathrm{ml}$ amidase-negative $R$ hodococcus cells, $1 \mathrm{ml} P$. putida cells (these contained about 40 nkat amidase activity) and $1 \mathrm{ml} 0.2 \mathrm{M}$-acetonitrile in phosphate buffer, was incubated at $25^{\circ} \mathrm{C}$ for $30 \mathrm{~min}$. Ammonia concentrations were determined directly (Burris, 1972) by mixing $2 \mathrm{ml}$ of sample with $2 \mathrm{ml}$ Nessler's reagent and $3 \mathrm{ml} 2 \mathrm{M}-\mathrm{NaOH}$ : the $A_{490}$ was recorded 5 min later.

\section{RESULTS \\ Growth studies}

The growth yield was approximately proportional to acetonitrile concentration between 0.05 and $0.25 \%(\mathrm{v} / \mathrm{v})($ Fig. 1). At $0.5 \%(\mathrm{v} / \mathrm{v})$ there was a marked reduction in molar yield, while at $3 \%(\mathrm{v} / \mathrm{v})$ growth was virtually inhibited.

Table 1 shows that of the ten amides tested only one, acrylamide, failed to support growth of the Rhodococcus sp. when supplied as either the sole source of $\mathrm{C}$ or $\mathrm{N}$. The corresponding

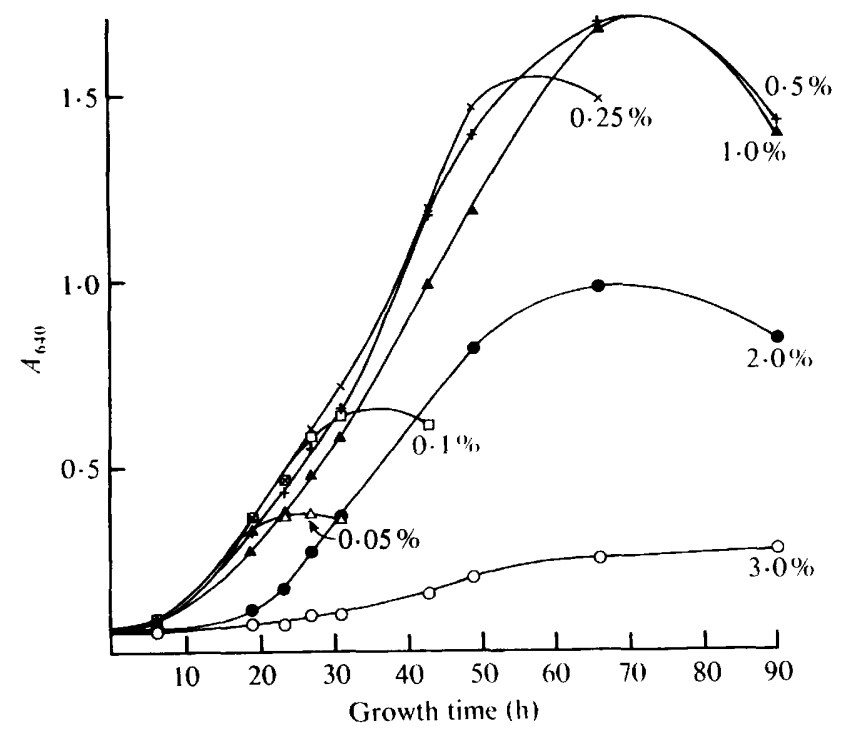

Fig. 1. Effect of acetonitrile concentration on the growth of the Rhodococcus sp. in minimal medium. 
nitrile, acrylonitrile, was also unable to support growth. The bacterium could not, however, grow with every nitrile whose corresponding amide was utilized, e.g. benzonitrile, phenylacetonitrile and malononitrile. 3-Aminoproprionitrile was a $\mathrm{N}$ source, but could not easily be tested as a $\mathrm{C}$ source since it was supplied as the fumarate salt.

\section{Hydrolysis of nitriles and amides by acetonitrile-grown cells}

When the reaction was allowed to go to completion, acetonitrile and acetamide gave $80 \%$ and $100 \%$, respectively, of the theoretical ammonia yields.

Of the amides, only acetamide, propionamide and acrylamide were rapidly hydrolysed, followed by formamide, $n$-butyramide and nicotinamide (Table 2). Cell extracts having substantial acetamidase activity, like intact cells, were apparently unable to release ammonia from benzamide, $\alpha$-phenylacetamide and malonamide even when the incubation period was extended to $120 \mathrm{~min}$. Thus the negative results obtained with intact cells were not simply due to permeability barriers.

The relative rates of hydrolysis of the nitriles did not parallel those of the corresponding amides. The rate of nitrile hydrolysis to yield ammonia decreased the greater the number of $\mathrm{C}$-atoms per molecule. Moreover, the introduction of a double bond, as in the $\mathrm{CH}_{3} \cdot \mathrm{CH}_{2}$ to $\mathrm{CH}_{2}: \mathrm{CH}$ conversion, stimulated the amidase but depressed the nitrilase.

\section{Table 1. Growth of the Rhodococcus sp. on various nitriles and amides}

Growth was positive if the $A_{640}$ of the culture increased to $>1.00$ within the $7 \mathrm{~d}$ incubation period. The non-growing cultures did not show any significant increase in $A_{640}$ during the same period.

\begin{tabular}{|c|c|c|}
\hline $\begin{array}{c}\text { Compounds supporting growth } \\
\text { when supplied as sole } \mathrm{C} \text { and } \mathrm{N} \\
\text { source }\end{array}$ & $\begin{array}{l}\text { Compounds supporting growth when } \\
\text { supplied as sole } \mathrm{N} \text { source }\end{array}$ & $\begin{array}{l}\text { Compounds not supporting } \\
\text { growth when supplied as } \\
\text { sole } \mathrm{C} \text { or } \mathrm{N} \text { source }\end{array}$ \\
\hline Acetonitrile & 3-Aminopropionitrile (+ fumarate) & Acrylonitrile \\
\hline Acetamide & Formamide ( + acetate or succinate) & Acrylamide \\
\hline Propionitrile & Malonamide $(+$ acetate or succinate $)$ & Malononitrile \\
\hline Propionamide & Nicotinamide ( + acetate or succinate) & Aminoacetonitrile (bisulphate) \\
\hline$n$-Butyronitrile & Benzamide $(+$ acetate $)$ & Benzonitrile \\
\hline n-Butyramide & Urea (+ acetate) & Phenylacetonitrile \\
\hline
\end{tabular}

$\alpha$-Phenylacetamide

\section{Table 2. Hydrolysis of nitriles and amides by acetonitrile-grown cells of Rhodococcus sp.}

Results are the averages of duplicate measurements. The value for HCN is scarcely greater than experimental uncertainty. Malononitrile, benzonitrile and phenylacetonitrile were not tested: the corresponding amides were not hydrolysed so the coupled assay would not have been valid. The hydrolysis rates are expressed as $n \mathrm{~mol} \mathrm{NH}_{3}$ produced $\min ^{-1}$ (mg dry wt cells) ${ }^{-1}$.

Nitrile

Hydrogen cyanide

Acetonitrile

Propionitrile

n-Butyronitrile

Acrylonitrile

Aminoacetonitrile

3-Aminopropionitrile
Hydrolysis

rate

0.3

$86 \pm 3$

$2 \cdot 1 \pm 0.1$

$0.87 \pm 0.01$

$27 \pm 4$

ND

ND
Corresponding amide

Formamide
Acetamide
Propionamide
$n$-Butyramide
Acrylamide
$\quad-$
-
Nicotinamide
Benzamide
$\alpha$-Phenylacetamide
Malonamide

Formamide

Propionamide

$n$-Butyramide

Acrylamide

Nicotinamide

$\alpha$-Phenylacetamide

Malonamide

$$
\begin{gathered}
\begin{array}{c}
\text { Hydrolysis } \\
\text { rate }
\end{array} \\
360 \pm 40 \\
2100 \pm 200 \\
9100 \pm 1200 \\
65 \pm 6 \\
4500 \pm 400 \\
- \\
- \\
1.6 \pm 0.4 \\
\text { ND } \\
\text { ND } \\
\text { ND }
\end{gathered}
$$

ND, Not detected. 
Table 3. Nitrilase and amidase activities in cells grown on different $C$ and $N$ sources

Acetonitrile was added to $0.25 \%(\mathrm{v} / \mathrm{v})$ and acetamide to $0.25 \%(\mathrm{w} / \mathrm{v})$. The concentrations of the other $\mathrm{C}$ and $\mathrm{N}$ sources are given in Methods. The starter medium for the last experiment contained no acetamide to avoid initial induction of the enzymes. Results are the averages of duplicate assays.

\begin{tabular}{|c|c|c|}
\hline \multirow[b]{2}{*}{$\begin{array}{c}\mathrm{C} / \mathrm{N} \text { source(s) } \\
\text { in growth medium }\end{array}$} & \multicolumn{2}{|c|}{ 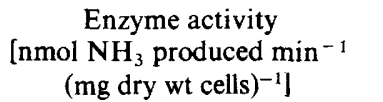 } \\
\hline & Acetonitrilase & Acetamidase \\
\hline Acetonitrile & $86 \pm 3$ & $2100 \pm 200$ \\
\hline Acetamide & $113 \pm 4$ & $1240 \pm 40$ \\
\hline $\begin{array}{l}\text { Sodium acetate } \\
+\left(\mathrm{NH}_{4}\right)_{2} \mathrm{SO}_{4}\end{array}$ & $17 \cdot 9 \pm 0.5$ & $520 \pm 20$ \\
\hline $\begin{array}{l}\text { Sodium succinate } \\
+\left(\mathrm{NH}_{4}\right)_{2} \mathrm{SO}_{4}\end{array}$ & ND & ND \\
\hline $\begin{array}{l}\text { Sodium succinate } \\
+ \text { Acetamide } \\
+\left(\mathrm{NH}_{4}\right)_{2} \mathrm{SO}_{4}\end{array}$ & $25 \cdot 1 \pm 0 \cdot 7$ & $363 \pm 4$ \\
\hline
\end{tabular}

ND, Not detected.

The hydrolysis of the aminonitriles to the corresponding amino acids and ammonia could fail to occur at either the nitrile or the amide level. Thus an NMR spectrometer was used to search for aminoamides in the relevant reaction mixtures. None were detected. Standards were used to determine the sensitivity of the spectrometer. These measurements suggested that the rates of hydrolysis of aminoacetonitrile and 3-aminopropionitrile to their corresponding amides cannot be greater than 1.7 and 3.4 , respectively, using the same units as in Table 2.

Several bacteria have been shown to transfer the acyl moiety of amides to hydroxylamine as well as to water (Clarke, 1970): this activity was also detected with the Rhodococcus sp. With acetamide as substrate the transferase activity was approximately ninefold greater than the equivalent amide hydrolase activity, i.e. $19600 \pm 30 \mathrm{nmol}$ acethydroxamate produced $\min ^{-1}$ (mg dry wt of cells) $)^{-1}$.

\section{Effect of various compounds on enzyme activity}

Compounds unable to act as effective substrates were tested as possible inhibitors or activators of nitrilase and amidase activities. Acetonitrile-grown cells were used for these experiments and the potential modifiers were supplied at the same concentrations as the substrates $(0.05 \mathrm{M})$.

With acetamide as substrate, nicotinamide and benzamide stimulated $\mathrm{NH}_{3}$ production by $19 \%$ and $18 \%$, respectively, in whole bacteria and by $44 \%$ and $14 \%$ in cell extracts. Malonamide had no significant effect on acetamidase activity. With acetronitrile as substrate, and bacterial suspensions which had been sonicated for $5 \mathrm{~min}$ so that 5 to $10 \%$ of the cells had been broken, aminoacetonitrile and 3-aminopropionitrile decreased $\mathrm{NH}_{3}$ formation by $85 \%$ and $30 \%$, respectively.

\section{Enzyme induction/repression studies}

Nitrilase and amidase activities were present in bacteria grown in minimal media containing acetonitrile, acetamide or acetate and $\left(\mathrm{NH}_{4}\right)_{2} \mathrm{SO}_{4}$ (Table 3). When acetamide was present, succinate and/or $\left(\mathrm{NH}_{4}\right)_{2} \mathrm{SO}_{4}$ reduced formation of these enzymes: when acetamide was omitted suppression was complete.

\section{DISCUS SION}

The Rhodococcus sp. used here is moderately tolerant of high acetonitrile concentrations and is similar to Nocardia rhodochrous LL100-21 in that growth is virtually inhibited at $3 \%$ 
(v/v) acetonitrile (DiGeronimo, 1975). Corynebacterium nitrilophilus nov. sp. C-42 will tolerate up to $5 \%$ (v/v) (Mimura et al., 1969), while the Pseudomonas species isolated by Firmin \& Gray (1976) will not grow even in $1 \%(\mathrm{v} / \mathrm{v})$ acetonitrile.

Bacterial amidases are commonly studied in intact cells by measuring the ammonia released into the medium. Here this approach has been extended to study the relative rates of nitrile hydrolysis in a species of Rhodococcus. Fortunately even in the most unfavourable case, the amide is hydrolysed 24 times faster than the nitrile, so the nitrilase reaction will be rate-limiting. These hydrolysis reactions are almost quantitative, especially in dilute bacterial suspensions like those used for the amidase assay. Thus they provide a convenient way of investigating the specificities of the relevant enzymes in vivo together with those of any linked transport systems.

The coupled assay itself has established that aminoacetonitrile is not a substrate for Rhodococcus nitrilase: it is now known that the conversion of glycinamide to ammonia occurs spontaneously and quantitatively during microdiffusion. The situation regarding 3-aminopropionitrile is less clear, though NMR measurements show that it was not a good nitrilase substrate. Thus, aminoacetonitrile itself must be an active inhibitor while 3-aminopropionitrile might have been hydrolysed to the corresponding amide before it was effective. Since these inhibitions were demonstrated in a predominantly whole cell system, they could be due to competition between the aminonitriles and acetonitrile for a permease.

The amidase induced in acetonitrile-grown cells could hydrolyse acrylamide rapidly although this compound could not support growth. Acrylamide may not itself be an amidase inducer, but it was tested as a $\mathbf{N}$ source in the presence of the proven inducer, acetate. Thus either acrylamide or its hydrolysis product, acrylic acid, is toxic or else acrylamide acts as a repressor of amidase synthesis in this Rhodococcus sp. Similar arguments apply to the results obtained for acrylonitrile.

Malonamide, benzamide and $\alpha$-phenylacetamide provide examples of the opposite situation: they are not substrates of the amidase present in acetonitrile-grown cells, but support growth. This suggests that the bacterium can synthesize more than one amidase. Although no ammonia was released from 3-aminopropionitrile, the growth-supporting properties of this nitrile are less certainly due to the induction of a new enzyme: NMR spectra show that 3-aminopropionitrile preparations include a one-carbon compound whose concentration increases with time. Thus, the $\mathrm{N}$ source in these growth experiments could be a chemical decomposition product.

The comparative rates of hydrolysis of the substrate amides by the Rhodococcus $\mathrm{sp}$. are very similar to those of induced cells of $P$. aeruginosa (Kelly \& Clarke, 1962). This is an interesting observation considering the diverse taxonomic positions of the two bacteria.

Rhodococcus, like C. nitrilophilus nov. sp. C-42 (Mimura et al., 1969), N. rhodochrous LL100-21 (DiGeronimo \& Antoine, 1976) and Arthrobacter sp. I-9 (Yamada et al., 1979) cannot utilize benzonitrile. However, N. rhodochrous (NCIB 11216) (Harper, 1977) can metabolize the compound, probably by hydrolysing it directly to benzoic acid. Here the amide appears not to act as an intermediate since it could not readily support growth or act as a substrate for benzonitrile-grown cells. This breakdown pathway is similar to that of ricinine in bacteria (Robinson \& Hook, 1964) and of indole-3-acetonitrile in higher plants (Thimann \& Mahadevan, 1958).

During some of the present induction/repression studies $P$. putida was used to provide added amidase. This technique requires that any acetamide produced by the Rhodococcus sp. should be released into the medium. This is a reasonable assumption since $N$. rhodochrous LL100-21 and C. nitrilophilus nov. sp. C-42 both release amide into the culture filtrate when growing in the presence of acetonitrile (DiGeronimo \& Antoine, 1976; Mimura et al., 1969).

Both the amidase and nitrilase of Rhodococcus are clearly subject to induction. DiGeronimo \& Antoine (1976) also found that the hydrolysis of acetonitrile by $N$. rhodochrous LL100-21 required prior induction, whereas the hydrolysis of $\alpha$-aminonitriles by 
Corynebacterium sp. HR3 to the corresponding amino acids was shown to be constitutive (Fukuda et al., 1971).

The results in Table 3 suggest that in Rhodococcus the nitrilase and amidase are induced and repressed by the same factors though not to the same degree. Succinate, or one of its metabolites, probably represses both enzymes, an example of the widespread phenomenon of catabolite repression. Acetonitrile-grown cells contain both enzymes, though it is uncertain whether the nitrile or its hydrolysis product, acetamide, is the effective amidase inducer. The gratuituous induction of the nitrilase by acetamide and of both enzymes by acetate also occurs in Brevibacterium R312 (Arnaud et al., 1977; Jallageas et al., 1978). The aliphatic amidase of $P$. aeruginos $a$ is also induced when grown in acetate medium (Clarke, 1970).

Thanks are due to Dr R. D. Farrant who operated the nuclear magnetic resonance spectrometer and interpreted the results.

\section{REFERENCES}

Arnaud, A., Galzy, P. \& Jallageas, J. C. (1976a). Remarques sur l'activité nitrilasique de quelques bactéries. Comptes rendus de l'Académie des sciences 287, 571-573.

Arnaud, A., Galzy, P. \& Jallageas, J. C. $(1976 b)$. Etude de l'activité nitrilasique de quelques bactéries. Revue des fermentations et des industries alimentaires 31, 39-44.

Arnaud, A., Galzy, P. \& Jallageas, J. C. (1976c). Amidase activity of some bacteria. Folia microbiologica 21, 178-184.

Arnaud, A., Galzy, P. \& Jallageas, J. C. (1977). Etude de l'acetonitrilase d'une souche de Brevibacterium. Agricultural and Biological Chemistry 41, 2183-2191.

Asano, Y., Tani, Y. \& Yamada, H. (1980). A new enzyme "nitrile hydratase" which degrades acetonitrile in combination with amidase. Agricultural and Biological Chemistry 44, 2251-2252.

Brammar, W. J. \& Clarke, P. H. (1964). Induction and repression of Pseudomonas aeruginosa amidase. Journal of General Microbiology 37, 307-319.

BurRIs, R. H. (1972). Nitrogen fixation-assay methods and techniques. Methods in Enzymology 24, 415431.

Clarke, P. H. (1970). The aliphatic amidases of Pseudomonas aeruginosa. Advances in Microbial Physiology 4, 179-222.

Clarke, P. H. (1972). Biochemical and immunological comparison of aliphatic amidases produced by Pseudomonas species. Journal of General Microbiology 71, 241-257.

Clarke, P. H. \& Richmond, M. H. (1975). Genetics and Biochemistry of Pseudomonas. London: Wiley.

DiGeronimo, M. J. (1975). The metabolism of acetonitrile by a Nocardia rhodochrous. Ph.D. thesis, Rutgers, The State University of New Jersey, New Brunswick, New Jersey, U.S.A

Digeronimo, M. J. \& Antoine, A. D. (1976). Metabolism of acetonitrile and propionitrile by Nocardia rhodochrous LL100-21. Applied and Environmental Microbiology 31, 900-906.

Etherington, J. R. \& MORREy, B. A. (1967). Nitrogen determination in nutrient cycling studies: an improved technique for handling multiple samples. Journal of Applied Ecology 4, 531-533.

Firmin, J. L. \& Gray, D. O. (1976). The biochemical pathway for the breakdown of methyl cyanide (acetonitrile) in bacteria. Biochemical Journal 158, 223-229.

Fukuda, Y., Fukui, M., Harada, T. \& Izumi, Y. (1971). Formation of $\alpha$-amino acid from $\alpha$-aminonitrile by cell suspensions of a strain of Corynebacterium. Journal of Fermentation Technology 49, 1011-1016.

Grant, D. J. W. (1973). Degradative versatility of Corynebacterium pseudodiphtheriticum NC1B 10803 which uses amides as carbon source. Antonie van Leeuwenhoek 39, 273-279.

HARPER, D. B. (1977). Microbial metabolism of aromatic nitriles. Biochemical Journal 165, 309319.

Jallageas, J. C., Arnaud, A. \& Galzy, P. (1978). Etude de l'acetamidase d'une souche de Brevibacterium. Journal of General and Applied Microbiology 24, 103-114.

Kelly, M. \& Clarke, P. H. (1962). An inducible amidase produced by a strain of Pseudomonas aeruginosa. Journal of General Microbiology 27, 305-316.

Mimura, A., Kawano, T. \& Yamaga, K. (1969). Application of microorganisms to petrochemical industry. (I) Assimilation of nitrile compounds by microorganisms. Journal of Fermentation Technology 47, 631-638.

Robinson, W. G. \& HoOK, R. H. (1964). Ricinine nitrilase. I. Reaction product and substrate specificity. Journal of Biological Chemistry 239. 4257-4262.

ThimanN, K. V. \& Mahadevan, S. (1958). Enzymatic hydrolysis of indoleacetonitrile. Nature, London 181, 1466-1467.

Yamada, H., Asano, Y., Hino, T. \& TANI, Y. (1979). Microbial utilization of acrylonitrile. Journal of Fermentation Technology 57, 8-14.

YAMADA, H., Asano, Y. \& TANI, Y. (1980). Microbial utilization of glutaronitrile. Journal of Fermentation Technology 58, 495-500. 